\title{
Um Arquivo sobre Teatro e Educação: problematizações no campo da invenção
}

\author{
Sidmar Silveira Gomes' \\ 'Universidade Estadual de Maringá (UEM), Maringá/PR - Brasil
}

RESUMO - Um Arquivo sobre Teatro e Educação: problematizações no campo da invenção. Inspirada no trato arquivístico legado pelo pensador francês Michel Foucault, esta reflexão debruçou-se sobre a tarefa de estabelecer um inventário da produtividade discursiva relativa ao campo das práticas que aliam teatro e educação, tomando por base empírica artigos concernentes ao tema e publicados em 58 periódicos da área educacional. Objetivou-se flagrar descontinuidades, regularidades e aleatoriedades em tal campo discursivo, culminando em mirar pela perspectiva crítica o que no presente emana certo ar de naturalização. Tal inventário alumbrou discursos regulares, além de embates entre as ditas abordagens essencialistas e contextualistas das práticas teatrais, resultando em efeitos atenuadores de suas distâncias conceituais.

Palavras-chave: Teatro e Educação. Pedagogia do Teatro. Arquivo. Michel Foucault.

ABSTRACT - An Archive on Theater and Education: problematizations in the field of invention. Inspired by the archival treatment left by the French thinker Michel Foucault, this reflection focused on the task of establishing an inventory of discursive productivity related to the field of practices that combine Theater and Education, adopting as an empirical basis, articles concerning the theme and published in 58 educational journals. The objective was to detect discontinuities, regularities, and randomness in such discursive field, culminating in looking through a critical perspective at what in the present emanates a certain air of naturalization. This inventory illuminated regular discourses, as well as clashes between so-called essentialist and contextualist approaches to Theater practices, resulting in mitigating effects of their conceptual distances.

Keywords: Theater and Education. Theater Pedagogy. Archive. Michel Foucault.

Educação \& Realidade, Porto Alegre, v. 46, n. 3, e104309, 2021. 


\section{Sobre o Arquivo}

A presente pesquisa está interessada, tomando como inspiração o trato arquivístico legado pelo pensador francês Michel Foucault e seus correligionários, em estabelecer um inventário, espécie de visão geral, acerca da produtividade discursiva relativa ao campo das práticas que aliam teatro e educação. Destarte, foram reunidos artigos concernentes ao tema e publicados em 58 periódicos da área educacional, em arco temporal que se estende da década de 1990 ao ano de 2019. Teve-se como fito, a partir de uma reflexão genérica, lançar luz sobre possíveis descontinuidades, regularidades e aleatoriedades no interior de tal campo discursivo, almejando mirar pela perspectiva crítica o que no presente emanaria certo ar de naturalização, condição, quiçá, constitutiva do que Conte, Habowski e Silva (2019) classificam como "[...] excessivo volume de discursos redundantes, mas que não conseguem ser traduzidos e mobilizados em práticas de reinvenção e renovação pedagógica e formativa” (p. 181). Inerente a isso, está a investigação das possíveis contribuições metodológicas do manejo arquivístico para pesquisas na área do teatro-educação.

Importa mencionar que tal investigação dá-se como parte preliminar do projeto de pesquisa docente As Potencialidades da Noção de Arquivo para Investigações no Campo da Pedagogia do Teatro (Departamento de Música e Artes Cênicas - Universidade Estadual de Maringá), etapa que elege como objetivo, conforme dito, o mapeamento da discursividade atinente às associações entre teatro e educação no interior de revistas do campo da Educação - lócus privilegiado de produtividade e circulação de tais discursos. Essa etapa pretende ser complementada, em pesquisa posterior, pelo mapeamento da produtividade discursiva de mesma temática, entretanto, no interior de revistas científicas do campo das Artes Cênicas.

Roberto Machado expõe que o trabalho de Foucault diante de seus arquivos e de sua empreitada arqueonealógica, pautou-se na tarefa de fazer

[...] descrições, e não prescrições, recorrendo à história para mostrar que aquilo que existe nem sempre existiu, como diz numa entrevista em 1983. A função do intelectual não é modelar o projeto político dos outros; é questionar as evidências, os hábitos, os modos de agir estabelecidos, as familiaridades adquiridas e, pelas análises que faz em seu domínio específico, participar das lutas políticas. A crítica é um instrumento de luta, de resistência (Machado, 2017, p. 116).

O interesse pela história por parte do pensador francês foi pautado na análise dos jogos de verdade: “[...] dos jogos do verdadeiro e do falso através dos quais o ser se constitui historicamente como experiência, ou seja, como podendo e devendo ser pensado" (Foucault, 2010, p. 195). Parafraseando tal ideia, interessou à presente reflexão investir no arquivo tomando-o pelo prisma da problematização por meio da qual 
o teatro aliado à educação, e os sujeitos aí envolvidos, se apresentam como podendo ser pensados, já que constituídos a partir de certas experiências educativas tidas no bojo de jogos de veridicção - compreendidos "[...] como as formas pelas quais se articulam, sobre um campo de coisas, discursos capazes de serem ditos verdadeiros ou falsos" (Foucault, 2010, p. 235) - e da estruturação das condutas de si e do outro (Foucault, 2004).

Tendo-se como norte a premissa de que "[...] o arquivo não diz a verdade, mas ele diz da verdade" (Farge, 2009, p. 35), o trabalho arquivístico perpetrado seguiu a esteira da operação correlativa dos procedimentos de arquivamento (manuseio inicial do conjunto de documentos, classificação e organização dos enunciados do arquivo) e de arquivização (olhar apurado frente à massa discursiva constituída, identificando as rupturas, continuidades e singularidades imanentes ao objeto de estudo), conforme equacionados por Aquino e Val (2018).

A ideia de arquivo que inspira esta empreitada é definida por Foucault como "[...] a massa das coisas ditas em uma cultura, conservadas, valorizadas, reutilizadas, repetidas e transformadas" (Foucault, 2014, p. 52), portanto, massa verbal "[...] fabricada pelos homens, investida em suas técnicas e suas instituições, e que é tecida com sua existência e sua história" (Foucault, 2014, p. 52).

Para Albuquerque Junior (2013), a relação dos pesquisadores com o arquivo não se restringe à ordem racional, “[...] os documentos emocionam, mexem com a sensibilidade do pesquisador, os documentos se tornam mais ou menos relevantes, se tornam dignos de eleição, de escolha, de seleção, de recolha, de registro e de citação pela emoção que causam no pesquisador" (p. 12). Por conta disso, a montagem de um arquivo exigiria "[...] arriscar-se a pôr, uns junto a outros, traços de coisas sobreviventes, necessariamente heterogêneas e anacrônicas, posto que vêm de lugares separados e de tempos desunidos por lacunas. Esse risco tem por nome imaginação e montagem" (Didi-Huberman, 2012, p. 211212). No bojo de ambos os pensamentos haveria um trabalho inevitavelmente criativo, de escolhas, de recortes, de colagens, de sobreposições e de relações que descortinariam as perspectivas de mundo e as referências do pesquisador que manipula tal massa documental. Portanto, o trabalho do pesquisador frente ao arquivo trata, no limite, de uma forma de dar-se ao mundo a partir dos efeitos do outro em si.

A escolha por artigos de revistas acadêmicas como arquivo empírico objetiva a análise dos jogos de verdade e da constituição dos sujeitos e de suas práticas, reconhecendo, assim, a Universidade como campo privilegiado de produção e de difusão de saberes.

Os periódicos que serviram de substrato ao arquivo desta pesquisa foram os seguintes: Cadernos CEDES, Cadernos de Pesquisa FCC, Currículo sem Fronteiras, Educação \& Sociedade, Educação e Pesquisa, Educação \& Realidade, Educação em Revista, Educar em Revista, Práxis Educativa, Pro-Posições, Revista Brasileira de Educação, Revista Brasileira de Estudos Pedagógicos, Revista Brasileira de História da Educação, 
Um Arquivo sobre Teatro e Educação

Revista História da Educação, Acta Scientiarum Education, Cadernos de História da Educação, Educação (PUC-RS), Educação (UFSM), Educação em Questão, Educação Temática Digital, Educação Unisinos, Perspectiva, Práxis Educacional, Revista da FAEEBA, Revista de Educação Pública (UFMT), Revista Diálogo Educacional, Revista E-Curriculum (PUCSP), Revista Eletrônica de Educação (São Carlos), Revista Ibero-Americana de Estudos em Educação, Roteiro, Teias, Cadernos de Pesquisa (UFMA), Eccos Revista Científica, Educação e Cultura Contemporânea, Educação: Teoria e Prática, Inter-Ação (UFG), Linguagens, Educação e Sociedade, Linhas Críticas (UNB), Retratos da Escola, Revista Comunicações, Revista de Educação, Ciência e Cultura, Série-Estudos (UCDB), Tempos e Espaços em Educação, Atos de Pesquisa em Educação (FURB), Cadernos de Educação (UFPel), Educação em Foco (UEMG), Educação em Foco (UFJF), Educação em Perspectiva, Em Aberto, Quaestio (UNISO), Reflexão e Ação, Revista Cocar, Revista de Educação PUC-Campinas, Revista Espaço Pedagógico, Revista Horizontes, Imagens da Educação, Revista Educativa e Cadernos de Pesquisa: Pensamento Educacional. Trata-se de revistas com classificação Qualis Periódicos A1, A2, B1 e B2 - Quadriênio 20132016.

O total de artigos publicados nas supracitadas revistas foi atravessado pelos termos teatro, pedagogia do teatro, pedagogia teatral e teatro-educação, por meio de busca simples, o que resultou em um arquivo com 123 artigos. Esses, foram classificados cada um, primeiramente, de acordo com as referências das revistas na qual foram publicados, o título, o(s) autor(es), o resumo e as palavras-chave. Após, foi feita a leitura de cada um dos textos, o que resultou na catalogação, por meio de planilha dividida em 3 colunas: 1) referências da publicação, 2) palavras e ideiaschave e 3) trechos-chave. Os passos descritos até aqui inspiraram-se nas proposições de Aquino e Val (2018) que concernem à ideia de arquivamento. A tabela constituída permitiu cotejar os discursos presentes em cada um dos textos, por meio de aproximações temáticas, identificação de similaridades, de regularidades, de rupturas, de contradições, de deslocamentos, de filiações teórico-metodológicas etc., resultando na reflexão abaixo apresentada. Vale frisar que essa etapa foi inspirada pelo procedimento que Aquino e Val (2018) chamam de arquivização.

\section{Sobre as Arbitrariedades e as Singularidades do Arquivo}

"Em que termos experiências formativas, mediadas por práticas teatrais, contribuem para a aprendizagem de conhecimentos socialmente relevantes e compreensão crítica e reflexiva da realidade?" (Freitas; Gonçalves, 2018, p. 200); “[...] afinal de contas, para que serve a arte? Para que serve a música, o teatro, a dança, as artes plásticas, o cinema?" (Troja, 1996, p. 87); “[...] quais são as contribuições da linguagem teatral para as experiências criativas e comunicativas na educação?" (Conte; Habowski; Silva, 2019, p. 164); “[...] por que razão na contemporaneidade o teatro na educação foi relegado e banalizado da condição humana e social de mundo?” (Conte; Habowski; Silva, 2019, p. 168); “[...] seria pos- 
sível uma alfabetização estética efetiva, no sentido do aprendizado de uma linguagem especificamente teatral? As aulas de teatro deveriam ficar apenas no nível da integração e sensibilização ou o trabalho poderia ser encaminhado em direção ao aprendizado dessa linguagem, por meio da montagem teatral?” (Rabello, 2007, p. 160); “[...] que sujeitos sujeitados construímos na Pedagogia, na Arte e na Educação?” (Vieira, 2008, p. 164); “[...] prática teatral na escola para quê? Para quem? A favor de quem? Contra quem?” (Kruppa; Voltas, 2016, p. 316); “[...] de que maneira um currículo-teatro concorre para o alargamento das vidas de alunos e professores?" (Oliveira; Paraíso, 2014, p. 959);

[...] o que já sabem as crianças e os jovens sobre música, dança e teatro, artes visuais? Trocando em miúdos, como trabalhar com um repertório inicial de maneira antropológica, o que significa levar em conta os modos de vida dos alunos e das comunidades às quais pertencem? Como cativar crianças e jovens para que eles mesmos desejem intensamente fazer música, dançar, fazer teatro, pinturas, esculturas e outras tantas criações, performances encarnadas em poéticas próprias? (Machado, 2012, p. 11);

“[...] teriam as artes cênicas um papel na formação do adolescente?” (Ipolito; Perdigão-Nass, 2016, p. 235);

[...] o ensino de artes está presente em todas as escolas brasileiras, cumprindo as determinações da LDB como disciplina obrigatória? Por que ainda algumas escolas oferecem o ensino de arte apenas em alguns anos de escolaridade ou sem exigir a formação específica do professor? Por que a disciplina é reduzida ou retirada da grade curricular, restringindo as possibilidades da formação artística e cultural do aluno? (Coutinho; Oliveira, 2015, p. 135);

“[...] sendo a educação - tal como a performance - um modo de expressão, o que de uma se aplicaria à outra? Que pontos de contato, de contaminação, existiriam entre ambas?" (Pereira, 2012, p. 290); “[...] de que maneira a recuperação da dimensão expressiva do ato pedagógico serve para desenvolver o pensamento e a prática educativa contemporânea? Seria o ato pedagógico um ato performático?” (Pereira, 2010, p. 151); "[...] pode o teatro transformar o sujeito em formação? Pode o sujeito, durante sua formação teatral, transformar-se para além da dimensão do trabalho?" (Alcântara; Icle, 2014, p. 463).

Da listagem de algumas das questões disparadoras das reflexões contidas nos artigos que compõem o presente arquivo, emergem categorias temáticas recorrentes. Antes de se partir para a delimitação dessas categorias, cabe salientar que o arquivo trouxe à tona duas pesquisas que, por conta de seus objetivos específicos, também se ocuparam da tarefa de categorizar as relações possíveis entre o teatro e a educação.

A revisão bibliográfica, as entrevistas exploratórias realizadas na pesquisa, bem como o levantamento de dissertações e teses no portal CAPES/MEC, permitiram delinear 
Um Arquivo sobre Teatro e Educação

quatro concepções que têm orientado as reflexões atuais sobre o papel do teatro na formação dos educandos. São elas: o teatro como instrumento didático; o teatro como instrumento potencializador de aspectos do desenvolvimento humano; o teatro como prática emancipatória e o teatro como entretenimento (Kruppa; Voltas, 2016, p. 311).

Resumindo, o teatro e a educação têm se relacionado de cinco maneiras diferentes: a) o teatro prestou-se a uma certa didática no ensino de diversos conteúdos; b) o teatro surgiu como uma disciplina curricular obrigatória desde a pré-escola; c) o teatro funcionou como performance organizadora de eventos sócio-culturais nas escolas; d) o teatro funcionou como uma atividade experimental organizadora de informações e sensações tanto a atores quanto a espectadores; e) a educação dramática surgiu como modalidade pedagógica de cunho estritamente pedocêntrico (Bareicha, 1998/1999, p. 129).

A presente pesquisa, como se verá, de posse de um arquivo outro, revela categorias próprias, ainda que próximas sob certos aspectos das classificações acima expostas, já que, conforme legado pelo gesto procedimental foucaultiano, os universais não existem, um mesmo objeto pode ser mirado por diferentes perspectivas, surgindo como diferente. Trata-se da evidenciação, portanto, da singularidade e da arbitrariedade inerentes aos discursos. Diferentes arquivos e diferentes documentos "[...] se fabricam, tanto quanto as narrativas que deles se utilizam" (Albuquerque Junior, 2013, p. 25).

Isto posto, as categorias por ora emergidas do presente arquivo são: 1) Formação inicial e/ou continuada de professores de teatro e de outras disciplinas; 2) Relações entre pedagogia e performance; 3) A utilização de conceitos do campo das práticas teatrais com o fito da teorização educacional; 4) Metodologias do ensino do teatro; e, por fim, 5) O emprego das práticas teatrais com finalidades precípuas outras que não a apropriação da própria linguagem.

É importante apontar, como se verá, que as categorias aqui enunciadas, não raro, têm suas fronteiras borradas, inclusive no interior de um mesmo artigo. A opção pela divisão pautada na ênfase do problema inerente a cada artigo serviu ao intuito primeiro de organizar a reflexão por ora manifestada.

Do corpus total dos artigos, 17 apresentam como eixo investigativo principal a formação inicial e/ou continuada de educadores, principalmente oriundos dos cursos de Pedagogia e Licenciatura em Artes e em Teatro. No que se refere a essa última habilitação, há a predominância de pesquisas de docentes a partir de experiências próprias e de seus alunos, originárias da disciplina de Estágio Supervisionado Obrigatório, as quais se debruçam sobre as dimensões do fazer teatral em ambientes da escola e da comunidade, conforme, por exemplo, o trabalho de Almeida Junior (2013), tributário do Estágio Supervisionado Obrigatório como fomento para, “[...] além das relações de ensino/aprendiza- 
gem formais associadas à epistemologia e práticas do ensino de teatro, estabelecer, a partir dele [estágio], espaços de ação cultural” (p. 53).

Além do ensino do teatro em cursos superiores interessados na instrumentalização dos discentes no que tange ao trabalho com a linguagem teatral - futuros professores de Artes, Teatro ou generalistas dos anos iniciais da educação básica e infantil-, o ensino do teatro também aparece empregado como instrumento para a formação inicial e continuada de educadores com o intuito de colocar "[...] em movimento as práticas docentes” (Abegg; Loponde, 2018, p. 601), ou, conforme Faria (2014), como “[...] instrumento de reflexão e de mudanç̧a de uma prática cristalizada" (p. 82), uma vez que a equipe de professores de uma instituição de ensino deve estar preparada para lidar com o inesperado, empregando respostas inusuais para os conflitos vividos. Nesse contexto, nomeadas como tecnologias teatrais por Almeida e Galas (2014), as práticas teatrais possibilitariam "[...] desenvolver habilidades de comunicação, liderança e criação para a formação acadêmica do fazer pedagógico, contribuindo no desenvolvimento de sujeitos críticos que tenham compreensão de seu papel em sociedade" (p. 48). Abrange-se, por isso, do ensino do teatro como linguagem para futuros pedagogos interessados no universo das Artes ao emprego do teatro como tecnologia, instrumento para o desenvolvimento e o aprimoramento de diferentes habilidades profissionais e, sobretudo, docentes.

A partir da década de 2010, avoluma-se a publicação de artigos que elegem como temática protagonista as interfaces entre pedagogia e performance. Esses trabalhos perfazem um total de 18 artigos no conjunto do arquivo. A evidência de quatro dossiês confirma o que se diz: Dossiê Performance, Performatividade e Educação, Educação \& Realidade, v. 35, n. 2, 2010; Dossiê Performance e Educação, Educação (UFSM), v. 39, n. 3, set./dez. 2014; Dossiê Performance e Escola, Caderno Cedes, 101, v. 37 , 2017; Dossiê Teatralidade, Performance e Educação, Educar em Revista, v. 34, n. 67, jan./fev. 2018.

Segundo Hartmann (2018) o tema dos estudos da performance passou " $[. .$.$] a despertar o interesse de educadores, devido à sua ênfase$ no diálogo, no olhar para o processo e por seu potencial crítico e transformador" (p. 931).

Tomando a ideia de performance como acontecimento de ampla significação e tendo como inspiração as reflexões do professor norteamericano Richard Schechner, tais pesquisadores coadunam suas ideias no pensamento de que:

O campo acadêmico dos Estudos da Performance diz: não vamos estudar apenas o teatro - ou qualquer outra forma de performance formal: dança, música, e outros -, mas estudar também as ruas, os lares, os escritórios - a partir do exame da vida cotidiana. Vamos estudar também a diversão popular: os esportes, os jogos, os filmes, a Internet, todo tipo de atividades. [...] Ensinar não constitui uma performance artística, mas certamente é uma performance. No ensinar, o professor precisa definir certas 
Um Arquivo sobre Teatro e Educação

relações com os estudantes. O professor precisa desempenhar o papel do professor, que pode variar de circunstância a circunstância (Icle; Pereira; Schechner, 2010, p. 29-30).

Assim, as pesquisas debruçadas sobre esse tema espraiam-se por reflexões que abrangem do campo da pedagogia da performance (André, 2017) ao campo das teorizações acerca de uma pedagogia performativa (Icle; Pereira, 2018). As primeiras estão interessadas em discutir, em linhas gerais, as possibilidades metodológicas das práticas performativas no âmbito de processos pedagógicos em Artes, portanto, refletem sobre processos performativos coordenados por professores de Artes desejosos por deflagrar, por meio do corpo dos alunos em jogo, “[...] experiências capazes de levar alguns estudantes a se descolarem de suas identificações, de sua ausência de crítica diante da ideologia da sociedade do capital, fazendo-os experienciar a diacronia com seu tempo" (André, 2017, n.p.). Já sobre o solo da pedagogia performativa, germinam as pesquisas que elaboram "[...] a sala de aula como espaço performativo" (Bonatto; Icle, 2017, p. 26), ou seja, a performance "[...] como operador para compreender e propor mudanças no âmbito da educação, significa, a um só tempo, a ritualização de comportamentos e a possibilidade inventiva de romper com essas repetições" (Bonatto; Icle, 2017, p. 11). Na mesma linha aponta o trabalho de Pereira (2014), o qual pretendeu

[...] Circunscrever a performance do professor como espaço de crítica e como metáfora para a reflexão; depreendendo da performance do professor seu caráter artístico e ritual; buscando, ainda, evidenciar o caráter parateatral da prática docente, a partir de diferentes configurações de professor que estabelecem atmosferas distintas e diferentes relações de ensino aprendizagem, seja favorecendo, seja comprometendo tais relações (p. 513).

$\mathrm{Na}$ imbricação dos temas da pedagogia da performance e da pedagogia performativa, emergem estudos interessados na identificação de traços de teatralidade, ou melhor, performatividade, na vida cotidiana, ou seja, "[...] não o teatro proposto pelo professor, mas um teatro que transborda da vida cotidiana, comentando-a, parodiando-a, apropriando-se dela" (Caon, 2017, p. 122). A percepção e a reflexão sobre os jogos, performances e performatividades aproximados pela pesquisadora e oriundos da corporalidade cotidiana dos sujeitos da escola objetivariam “[...] certa suspensão num fluxo cotidiano, intensificando ou esgarçando tempos, espaços e movimentos ao se delinearem. Tais experiências ressignificam as corporalidades dos sujeitos - agregam, sedimentam, reorganizam elementos nelas" (Caon, 2017, p. 125). Sobre o gesto cotidiano, agora das crianças, Machado (2010) defende a tese de que "[...] a criança é performer de sua vida cotidiana, suas ações presentificam algo de si, dos pais, da cultura ao redor, e também algo por vir" (p. 123). 
Portanto, seja como gatilho para repensar as práticas educativas a partir de perspectivas criativas que privilegiam a presença interativa e sensível dos corpos, ou como caminhos investigativos de criação e fruição artística, ambos, consequentemente, interessados em configurações outras, sensíveis e políticas de ser e estar no mundo, o arquivo constituído sugere que a aliança entre pedagogia e performance teria operado um possível deslocamento, desde o início do século XXI, no que tange às práticas que aliam teatro e educação, antes calcadas, sobretudo, na proposição de jogos teatrais e dramáticos. Ainda que demonstrem abdicar de escolhas metodológicas corriqueiras, os artigos desse grupo - conjunto que equivale a aproximadamente $14 \%$ do total de artigos do presente arquivo - evidenciam que essa espécie de alargamento incipiente dos horizontes metodológicos e intencionais das práticas que aliam teatro e educação parece ainda não asseverar força suficiente para operar cisões significativas no interior das discussões do campo em tela, conforme se verá, sobretudo, a partir deste ponto.

O emprego de conceitos do campo das práticas teatrais como mote para a teorização educacional é outra categoria emanada do arquivo. Como exemplo, pode-se citar o estudo de Coutinho (2018) interessado em "[...] discutir a potencialidade do conceito de improvisação, em especial quando usado no teatro - tendo como referência Spolin (2015), Ryngaert (2009) e Chacra (2010) -, para pensarmos temas típicos da didática, em suas relações com os espaços e os tempos educativos" (p. 123). O pesquisador complementa expondo encarar os "[...] processos didáticos de ensinar e aprender como atos de criação pedagógica” (p. 125), já que, por essa abordagem didática, na qual se jogaria com o saber, o conteúdo escolar não se apresentaria como primordial, mas se revelaria como um estado de potência, inerente aos sujeitos implicados nesse processo educativo.

Contribui na mesma medida para essa categoria os estudos de Oliveira e Paraíso (2013). Aproximando o Teatro da Crueldade de Antonin Artaud à Filosofia da Diferença de Gilles Deleuze, os autores friccionam crueldade, ética e cultura "[...] para tramar uma composição entre currículo e crueldade” (p. 617), teorizam, dessa forma, sobre a implementação de "[...] uma pedagogia do combate que age por uma violência às sensibilidades para tirar as formas de vida do entorpecimento ineficaz que os currículos tal como estão aí colocam” (p. 629).

Ao todo são quatro os artigos dessa seara, engajados em, a partir de ensaios teóricos que se valem instrumentalmente de conceitos teatrais, rever, em especial, os discursos acerca do currículo e da didática, almejando uma suposta ideia de pedagogia criativa.

Elegem como campo de problematização a exploração de metodologias do ensino do teatro, 37 artigos do arquivo constituído, principalmente a partir da realização de trabalhos práticos, seja em contextos da educação formal ou não formal. Tais pesquisadores mostram-se interessados tanto na exploração de caminhos outros para o ensino do teatro, quanto na aplicação de metodologias já consagradas no campo, 
adaptadas às especificidades do trabalho empreendido. Trata-se, na maioria, de propostas calcadas em procedimentos de pesquisa de campo de caráter qualitativo, observação participante, pesquisa participante e entrevistas semiestruturadas, desejosas de "[...] uma nova maneira de pensar as relações entre o conhecimento teatral e a experiência social dos estudantes" (Santos, 2005, p. 240). Para tanto, privilegiam “[...] ampliar o espaço em que a educação ocorre, passando-o da dimensão cognitiva, psicológica para a dimensão simbólica" (Thomaz, 2007, p. 50). Dessa forma, tais experimentações questionam o entendimento das práticas do teatro em contextos educacionais como a realização de

[...] 'clássicas' montagens cênicas (denominadas pelos próprios professores de 'teatrinhos', ou 'pecinhas', inspiradas em contos infantis ou ilustrativas dos eventos previstos no calendário escolar), das quais participam até mesmo as crianças bem pequenas (na faixa dos dois aos quatro anos de idade), que nem se quer são capazes de compreender o significado das ações e dos diálogos que, a duras penas (refiro-me aos métodos autoritários e coercitivos utilizados para assegurar a disciplina e o cumprimento dos desígnios do professor) conseguem memorizar e repetir (Santos, 2005, p. 239).

Conforme refletem Conte, Habowski e Silva (2019), essas abordagens do ensino do teatro se portariam como uma resposta ao que foi proposto pelos Parâmetros Curriculares Nacionais, documento de 1998 que reforçava "[...] a aplicação do teatro em sala de aula, como instrumento para uma formação integral, num sentido de totalidade, trazendo a multiplicidade das intuições dadas na imaginação e na arte da expressão" (p. 171). Vale frisar que, ainda que tais práticas reconheçam o teatro ou a Arte como disciplina autônoma, enfatizando uma abordagem essencialista do teatro, conforme se verá adiante, novamente serve-se da disciplina teatral pela justificativa de um uso instrumental, nesse caso, para o desenvolvimento integral do educando.

Há, como se vê, no interior desse grupo de artigos, duas vertentes predominantes: as que se utilizam do relato de uma prática teatral acompanhada de reflexão teórica, e as que teorizam sobre metodologias mestras do ensino do teatro.

No campo das primeiras, percebe-se um esquema de estrutura das reflexões que segue a explanação inicial acerca da metodologia de trabalho, com detalhamento de dados dos sujeitos que a sistematizaram, influências herdadas, espaços e tempos em que a prática surgiu, bases conceituais acompanhadas de relatos de experiências práticas, geralmente, conduzidas pelos próprios pesquisadores, a partir de recortes temáticos e/ou metodológicos aos quais se deseja investigar. Como exemplo disso, pode-se citar artigo de autoria da pesquisadora Peric (2013), que desenvolveu um projeto teatral no âmbito de uma Escola Municipal de Iniciação Artística na cidade de São Paulo, com um grupo de adolescentes de 11 e 12 anos, cujo objetivo foi a apropriação da linguagem teatral e o desenvolvimento da autonomia dos jovens parti- 
cipantes, utilizando-se de jogos dramáticos propostos por Jean-Pierre Ryngaert. A escolha pelo professor francês como inspiração ao trabalho da pesquisadora se justificaria “[...] não só pelo conhecimento acerca do teatro e do jogo dramático, mas, especialmente, pelo grande humanista que se revela perseverante, crente na sensibilidade e na invenção do ser humano" (p. 215). Da mesma forma, Serrano Junior (2008) discorre sobre as práticas do Teatro do Oprimido, de Augusto Boal, desenvolvidas em penitenciárias de diversos estados brasileiros, que tiveram como objetivo fazer com que servidores penitenciários incipientes na linguagem teatral se tornassem "[...] multiplicadores de uma metodologia que traz à tona não só as mazelas, mas as especificidades de um complexo e viciado sistema prisional que talvez nunca venha a ser perfeito, mas, com certeza, nunca mais será o mesmo" (p. 290). Alves e Nascimento (2018), no mesmo diapasão, discorrem sobre a proposição do recurso inclusivo da audiodescrição, destinado a alunos cegos de uma escola pública, como modalidade de mediação teatral e, consequentemente, de formação de espectadores. A experiência inspirou-se no modo de escrita inventivo característico de Manoel de Barros, no qual práticas de desinvenção de objetos, palavras e imagens foram empregadas em um processo que vislumbrou a metodologia improvisacional, calcada nos Jogos Teatrais de Viola Spolin, como complemento ao recurso da audiodescrição em processos de fruição teatral de alunos cegos.

Não raro, os pesquisadores recorreram a pensadores de áreas exógenas às práticas teatrais, tais como filósofos, psicólogos, sociólogos, entre outros, como inspiração teórica e, em parte, também metodológica, para adensar seus insights. Nesse sentido, pode-se citar o trabalho de Brito e Crusoé (2018), o qual "[...] se apoiou nos princípios teóricos e metodológicos da fenomenologia schutziana, para entender que tipo de experiência subjetiva nasce do encontro entre consciência e mundo da vida e para conhecer aspectos subjetivos que permeiam a relação com o outro" (p. 1257). Para isso, o pesquisador serviu-se de uma prática do Teatro do Oprimido em consonância aos interesses das experiências formativas de Paulo Freire, ambas alicerçadas sobre ideias libertárias. Como mais um exemplo, pode-se citar o trabalho de Japiassu (1998), o qual foi motivado pelo interesse em explorar no interior de uma prática de Jogos Teatrais, com crianças e jovens matriculados em uma escola pública, a operação do vocabulário vigotskianos calcado em conceitos como desenvolvimento cultural, processo ontogenético de formação de conceitos e zona de desenvolvimento proximal.

Cabe um parêntese para salientar que não só nessa categoria os autores recorrem a estudos exógenos às práticas teatrais como inspiração teórico/metodológica. Entre as figuras mais empregadas e seus respectivos conceitos, levando-se em consideração a totalidade dos artigos analisados, pode-se citar: Vygotsky (psicologia cultural, processo ontogenético de formação de conceitos, zona de desenvolvimento proximal, teoria histórico-cultural do desenvolvimento), Bakhtin (interação e discurso, análise do enunciado, cronotopo), Merleau-Ponty (fenomenologia), Dewey (experiência estética), Larrosa (experiência), Paulo Freire 
Um Arquivo sobre Teatro e Educação

(Pedagogia do Oprimido), Deleuze (desterritorialização, agenciamento, devir), Bachelard (devaneio), Alfred Schutz (fenomenologia das relações sociais), Félix Guattari (eco-lógica), Edgar Morin (consciência ecológica, ecossistema), Foucault (disciplina, cuidado de si, escrita de si, discurso, dispositivo, atos de verdade, loucura, linguagem, sexualidade, saber-poder).

Ressalta-se que a presente pesquisa, de acordo com o que se vê, não apresenta como objetivo específico mapear os trabalhos que tomam Foucault como fundamento para investigações no campo das práticas teatrais. Mesmo sem ser essa a intencionalidade primeira deste estudo, o que o arquivo operado demonstra, por meio, por exemplo, da lista acima apresentada, é que frequentemente o pensador francês é empregado de forma conceitual nas pesquisas no interior dessa área. Quiçá esse seja o mote para uma outra investigação. Nesse sentido, o interesse norteador dos passos da presente pesquisa endereça-se, sobretudo, ao Foucault procedimental, quer se diga, ao seu trato com o arquivo e as implicações que dele emergem. Isso posto, torna-se relevante também dizer que dos 123 artigos constituintes do arquivo de trabalho, 13 citam Foucault, mas nenhum se debruça enfaticamente sobre a investigação de seus gestos procedimentais de pesquisa.

Fechado o parêntese, entre as pesquisas interessadas na teorização das metodologias do ensino do teatro, sem estarem fundadas em práticas específicas realizadas pelos pesquisadores, pode-se citar o estudo de Gohn e Hansted (2013). Partindo de ensaio no qual as autoras discorrem sobre a relação historicamente constituída entre o teatro e a educação, são indicadas pesquisas significativas sobre práticas pedagógicas de caráter lúdico: “[...] obras como as de Cabral (2006, 2012), Chacra (2010), Pupo (1991, 1997), Reverbel $(1989,1997)$ e Vianna e Strazzacappa (2001)” (p. 212), além de “[...] as contribuições de Koudela (1992, 1999) e Japiassu $(1999,2007,2009)$, cujos estudos nos têm servido de importante referência na elaboração deste trabalho" (p. 213). Com o mesmo intuito, Costa, Munhoz e Schneider (2016) apresentam um ensaio teórico no qual aproximam o Teatro do Oprimido de Augusto Boal a práticas de educação popular. Já Pupo (2005) discorre, a partir de conceituações, especificidades e aproximações recíprocas, sobre os Jogos Teatrais sistematizados pela americana Viola Spolin, sobre os jogos dramáticos infantis conceituados pelo inglês Peter Slade, e sobre os Jogos Dramáticos de acepção francesa, os quais encontram como referência contemporânea o professor e teórico Jean-Pierre Ryngaert. No mesmo caminho, anos antes, foi posto à mostra o trabalho de Japiassu (1998), o qual, além de versar sobre o Jogo Teatral e o Jogo Dramático, trouxe à baila contextualizações e aproximações entre o Psicodrama de Jacob Levy Moreno, a Peça Didática de Bertolt Brecht e o Teatro do Oprimido de Augusto Boal.

Como observa-se, é recorrente ao longo das pesquisas expostas a referência a nomes como os de Bertolt Brecht, Viola Spolin, Jacob Levy Moreno, Jean-Pierre Ryngaert, Augusto Boal e Olga Reverbel como raízes fundantes das pesquisas nacionais em teatro e educação no que 
tange a inspirações metodológicas. Flagra-se em solo nacional a emergência de uma geração de pesquisadores, atuantes a partir da década de 1970, responsáveis pela disseminação das práticas e reflexões desses nomes, sobretudo, por meio da implementação de pesquisas próprias no campo. Entre esses, pode-se citar Koudela, Pupo, Cabral, Chacra e Japiassu. Portanto, esses últimos pesquisadores se tornam, como revela o arquivo, figuras-chave no que tange à dinamização da maquinaria da pesquisa em teatro e educação e, consequentemente, da discursividade que a retroalimenta. Por fim, tanto os inspiradores quanto os inspirados, inventores dessas espécies de metodologias mestras, despontam como protagonistas de pesquisas que se debruçam, inclusive, sobre outras discussões para além da seara das metodologias do ensino do teatro, como já se tem visto e se seguirá vendo ao longo deste trabalho.

Outra categoria acerca do que diz o arquivo, a qual disputa o protagonismo com a categoria das metodologias do ensino do teatro, é a que se vale assumidamente do usufruto das práticas teatrais como utilitárias a objetivos outros. É no interior de tal categoria que emerge explicitamente uma discussão iniciada na segunda metade do século XX e que, como indicado pelo arquivo, perdura hodiernamente: o fato de que "[...] o teatro apresenta duas correntes de ensino que podem ser utilizadas na educação" (Conte; Habowiski; Silva, 2019, p. 177). Animadas pelas discussões de Reverbel (1997), Conte, Habowiski e Silva, caracterizam tais correntes como:

[...] A primeira chama-se contextualista, onde a ação teatral é utilizada para a fixação de conteúdo, como, por exemplo, em uma aula de história para detalhamento dos fatos. A segunda corrente denomina-se essencialista, onde o teatro é utilizado para promover o desenvolvimento do educando, não alicerçado em nenhuma disciplina do currículo. Ambas as correntes são produtivas para a educação, cabendo ao professor definir de acordo com os objetivos almejados qual delas melhor extrai do mundo concreto aquilo que é necessário para a expressão dos significados, pensados e sentidos, da realidade de seus educandos (Conte; Habowiski; Silva, 2019, p. 177).

Essa questão também marca presença na reflexão de Cebulski, Loos-Sant'ana e Sant'ana-Loos (2013), pesquisadores que se remetem a Japiassu para frisar que, embora o ensino do teatro possa estar dividido entre as vertentes contextualista e essencialista, “[...] no plano da prática pedagógica essas duas dimensões se mostram presentes, ora com fronteiras bem definidas, ora se interpondo, interpenetrando-se" (p. 67). O próprio Japiassu (1998) destaca que a vertente contextualista, de tendência instrumental, estaria interessada no emprego do teatro como ferramenta didática para o ensino de diferentes disciplinas do currículo, em oposição, portanto, à vertente essencialista, de tendência estética, a qual conceberia o teatro como linguagem, cujo objetivo como disciplina escolar não seria necessariamente o de formar artistas, mas proporcionar ao aluno “[...] o domínio, fluência e compreensão estética 
Um Arquivo sobre Teatro e Educação

destas complexas formas humanas de expressão que movimentam processos afetivos, cognitivos e psicomotores" (p. 186).

Barros, Barros, Ferreira e Paschoal (2019) ressaltam que, mesmo se aproveitando do teatro para fins outros, é “[...] indispensável que o professor domine técnicas, neste caso em específico as teatrais" (p. 1213). Os artigos revelam o emprego das práticas teatrais a favor dos mais variados objetivos: "[...] o teatro constituiu um território de "exercício de si', instrumento para lidar com a vida e com o outro" (Ziliani, 2013, p. 260), “[...] o entusiasmo das crianças e o depoimento dos professores sobre os resultados conseguidos com as atividades desenvolvidas foram gratificantes e justificaram, mais uma vez, o uso do palco como instrumento pedagógico de relevância" (Caetano; Ribeiro, 1994, p. 5), "[...] essa funcionalidade docente significa exercer o ensino com criatividade e criticidade, aspectos que podem ser considerados ao fazermos uso do teatro como um instrumento de ensino e de aprendizagem" (Freitas; Gonçalves, 2018, p. 204), "[...] defende-se aqui que a Arte e o teatro, assim melhor dimensionados, podem ser resgatados como instrumentos fundamentais na formação dos cidadãos do amanhã" (Cebulski; Loos-Sant'ana; Sant'ana-Loos, 2013, p. 69); “[...] a arte teatral pensada como ferramenta de crescimento pessoal vai desencadear atitudes autônomas e conscientes nos jovens" (Grazioli, 2008, p. 14); "[...] as ações desenvolvidas corroboram com estudo brasileiro que trata do teatro como uma ferramenta de difusão do conhecimento que se quer tratar e de forma lúdica que ultrapassa a atividade de brincar, a criança passa a se interessar mais pelo conteúdo abordado" (ArakawaBelaunde; Padilha; Rodrigues; Silveira, 2019, p. 504); “[...] o teatro como estratégia pedagógica ressignificou e aprofundou as concepções dos alunos acerca do álcool e de seus efeitos na vida das pessoas" (Dal-Farra; Gonçalves, 2018, p. 419); “[...] propõe ainda pensar a prática teatral como metodologia para a alfabetização e letramento nos anos iniciais do Ensino Fundamental" (Barros; Barros; Ferreira; Paschoal, 2019, p. 1207); “[...] em outras palavras, ele [teatro] é um recurso para a catequese - portanto, para a educação - e parte integrante do projeto colonizador lusitano" (Bitar; Ferreira Jr., 2004, p. 174); “[...] pode-se afirmar que o teatro do CERA participou como elemento do dispositivo de escolarização na configuração identitária de Mato Grosso do Sul, naquele lugar e no período histórico datado" (Ziliani, 2016, p. 731); “[...] objetiva-se discutir a importância do teatro e sua relação com a educação no sentido de considerar os benefícios que esta linguagem pode proporcionar para o trabalho pedagógico na sala de aula, pensado como um elemento metodológico na prática de letrar e alfabetizar" (Barros; Barros; Ferreira; Paschoal, 2019, p. 1206); “[...] é possível, com o teatro, aprender conteúdos de diversas disciplinas escolares. História, geografia, literatura, idiomas e, particularmente, língua portuguesa, podem ser trabalhados de uma maneira atraente e interessante tanto para o aluno como para o professor" (Oliveira; Stoltz, 2010, p. 90), “[...] é corrente, nos dias de hoje, o senso comum de que os espetáculos teatrais podem ser facilitadores da educação, principalmente quando codificam conteúdos curricula- 
res, tais como textos da literatura brasileira, ensino de química, física, história, ou até mesmo “lições morais'” (Kruppa; Voltas, 2016, p. 312).

A esses incorporam-se outros usos: teatro como estratégia para a educação inclusiva de crianças com síndrome de Down (Cintra; Oliveira; Veiga, 2015); teatro de fantoches como recurso didático-metodológico para a formação continuada em educação ambiental (Dantas; Nakayama; Santana, 2012) e para o ensino de matemática (Fraga; Hundertmarc; Pozebon; Silva; Lopes; Pereira, 2012); teatro como recurso didático-metodológico para o ensino de ciências (Ataíde; Freire; Silveira, p. 2009), de física (Pieri; Rosa, 2017) e para promoção de ações da saúde em relação à temática do bullying (Arakawa-Belaunde; Padilha; Rodrigues; Silveira, 2019); teatro de objetos como um recurso para amenizar os traumas causados em crianças e adolescentes internados em ambiente hospitalar (Medina, 2018); teatro como recurso pedagógico e terapêutico no desenvolvimento psicossocial de pessoas portadoras de deficiência mental (Castro, 1995).

A partir da exaltação da abordagem interdisciplinar, uma parcela significativa dos trabalhos citados resulta em montagens teatrais a serem apresentadas pelos alunos à comunidade escolar, cujas temáticas são os conteúdos curriculares de interesse. Nesses processos os alunos se responsabilizam pela criação da dramaturgia de trabalho, pela direção cênica, bem como pela concepção e confecção de cenários, figurinos, elementos cênicos etc., orientados pelo professor responsável pela disciplina, nesses casos, não teatral.

Já outros trabalhos dessa categoria optam em suas armações argumentativas por detalhar os processos de trabalho, evidenciando as metodologias empregadas, lançando mão, geralmente, das já citadas metodologias mestras. Como exemplo, pode-se recorrer à prática desenvolvida por Dal-Farra e Gonçalves (2019), que objetivou o emprego do teatro como recurso didático-pedagógico para o ensino em saúde, valendo-se da relação prática entre o Teatro do Oprimido de Augusto Boal e o Teatro da Espontaneidade de Moreno. Japiassu (2000) empregou os Jogos Teatrais de Viola Spolin como recurso didático-metodológico ao objetivo de ensinar conceitos matemáticos para crianças.

Percebe-se do emprego contextualista das práticas teatrais a justificativa de que "[...] a emoção e a riqueza de recursos inerentes à linguagem do teatro contribuiriam para que conteúdos densos das ciências, principalmente, das ciências ditas exatas, fossem transmitidos de uma forma mais acessível, lúdica e prazerosa aos educandos" (Kruppa; Voltas, 2016, p. 312). Já do lado essencialista, as práticas teatrais seriam interessantes pois “[...] a arte dramática é capaz de resgatar o indivíduo em sua totalidade, ou seja, permitir-lhe transitar livremente por hemisférios distintos e integradores da essência humana, ir do emocional ao racional, do racional ao intuitivo, do intuitivo ao que está armazenado na memória" (Grazioli, 2008, p. 10).

Pelo exposto, se na explanação da categoria anterior explicitou-se a discursividade relativa às metodologias de ensino do teatro, pode-se 
Um Arquivo sobre Teatro e Educação

explicitar que neste ponto são revelados, por meio de um corpus de 47 artigos, os dizeres concernentes a práticas tributárias do emprego de metodologias de ensino pelo teatro.

\section{Sobre Arquivo e Invenção}

Tangenciando de certa forma grande parte das categorias elencadas, a discursividade atinente ao emprego das práticas teatrais com finalidades precípuas outras que não a apropriação da própria linguagem, dá a ver jogos de veridicção significativos ao campo do teatro-educação. Trata-se de um embate entre qual abordagem seria mais ou menos verdadeira, mais ou menos efetiva como recurso para a educação dos cidadãos. Os usos reiterados por parte dos pesquisadores aqui mobilizados das práticas teatrais como instrumento, ferramenta, estratégia, metodologia, recurso, dispositivo, elemento, diminuiriam as distâncias entre abordagens essencialistas e contextualistas, inclusive, porque, como visto, ambas advogam enfaticamente a favor das aludidas inegáveis e benéficas contribuições educativas inerentes a tais práticas, ainda que Oliveira e Stoltz (2010) atentem ao fato de que "[...] não se pretende dizer que o teatro ou qualquer outra atividade artística sejam os redentores da humanidade ou da escola" (p. 91).

Parafraseando o gesto procedimental foucaultiano, o que se procurou não foram relações secretas, escondidas, mais silenciosas ou mais profundas do que a consciência dos homens, mas sim ocupar-se da superfície dos discursos, intentando "[...] tornar visível o que só é invisível por estar muito na superfície das coisas” (Foucault, 2008a, p. 146). A montagem aqui operada dessa espécie de quebra-cabeça discursivo, sem esforços, evidencia que distintas peças das abordagens do teatro na educação, inclusive as que se tacham de essencialistas, se encaixam a favor das mesmas intencionalidades, as quais estariam para além das práticas teatrais per se. A faceta invisível disso diria respeito à naturalização da ideia das benéficas contribuições teatrais como inerentes a uma certa concepção de teatro dada desde sempre, essencialista, mesmo que contextualista, contextualista, mesmo que essencialista, conforme pode-se extrair da reflexão de Alves e Nascimento (2018):

\footnotetext{
Recusamos, porém, a postura do 'teatro para desenvolver a imaginação', visto que acreditamos que assim como a improvisação é imanente ao teatro, o desdobramento da imaginação é uma consequência intrínseca, uma condição sine qua non da imersão nessa linguagem. Logo, o estudo dessa linguagem não deve ser visto como 'estratégia para', mas como relevante em si mesmo (p. 228).
}

De forma geral, a discursividade aqui exposta extrapola o campo das práticas teatrais reunindo a atualização de palavras de ordem do campo educacional como um todo, interessadas, como visto, em proporcionar aos sujeitos outras relações criativas com os espaços e os tempos cotidianos, consigo e com o outro, por meio de processos libertários e emancipatórios que privilegiem a dimensão simbólica em detrimento 
das dimensões cognitivas e/ou psicológicas. A aliança entre as práticas do teatro e da educação nutre-se de tais palavras, na mesma medida em que a elas se presta como campo fértil de invenção.

Portanto, quando uma discursividade se serve em uníssono das essencialidades atribuídas às práticas teatrais, ignora-se o fato de que “[...] qualquer concepção que se julgue eterna tem uma história, 'deveio'” (Veyne, 2009, p. 116). As práticas teatrais foram inventadas, construídas, emergiram de irrupções, cisões arbitrárias, inauguração de valores e atribuições. Como manifesta Veyne, “[...] Foucault pensa que não existem verdades gerais, trans-históricas, porque os factos humanos, actos ou palavras, não provêm de uma natureza, de uma razão que seriam a sua origem, nem reflectem fielmente o objecto para o qual remetem" (2009, p. 17). Nesse sentido, as práticas teatrais aliadas à educação, quando abordadas pela perspectiva crítica daquilo que, no presente, é tido como naturalizado, desvelam o funcionamento da sofisticada maquinaria de como a conexão entre uma série de práticas e um regime de verdade constitui um dispositivo de saber-poder (Foucault, 2008b), substrato na mesma medida dos regimes que constituem os sujeitos e movimentam o governo das condutas de si e do outro.

O presente arquivo, "[...] como existência acumulada de discursos" (Foucault, 2008c, p. 72), que não permaneceriam “[...] em suspenso, nos limbos ou no purgatório da história, mas também como um conjunto que continua a funcionar, a se transformar através da história, possibilitando o surgimento de outros discursos" (Foucault, 2008a, p. 145), forjaria o pensamento de Conte, Habowski e Silva (2019), exposto no início desta reflexão. Cabe rememorá-lo: existiria no âmbito das práticas do teatro-educação "[...] um excessivo volume de discursos redundantes, mas que não conseguem ser traduzidos e mobilizados em práticas de reinvenção e renovação pedagógica e formativa" (Conte, Habowski e Silva, 2019, p. 181).

Como pode-se notar, é crucial apensar à reflexão acima o fato de que haveria um latente desejo de reinvenção dos percursos do teatroeducação despontado no âmago das intencionalidades que associam pedagogia e performance. Porém, conforme descortina o arquivo aqui mobilizado, trata-se de um desejo ainda incipiente. Quiçá sua debilidade encontre justificativa no fato de que seus caminhos acompanham, mesmo que por outros passos, as mesmas finalidades naturalizadas e redentoras dos movimentos de que parece querer se dissociar: desenvolver o potencial crítico, libertário e transformador dos sujeitos. Disso, pode-se concluir que, no que concerne ao campo das pesquisas endereçadas ao tema do teatro e da educação, o giro necessário, para que não seja em falso, talvez não deva se pautar na perspectiva de uma dita reinvenção, mas tão somente de abruptas invenções ${ }^{1}$.

Recebido em 22 de julho de 2020 Aprovado em 29 de março de 2021 


\section{Nota}

1 Educação \& Realidade informa que a publicação deste estudo foi em parte financiada pela Coordenação de Aperfeiçoamento de Pessoal de Nível Superior - Brasil (CAPES) - Código de Financiamento 001.

\section{Referências}

ABEGG, Fabiano Hanauer; LOPONTE, Luciana Gruppelli. O Que a Docência Pode Aprender com o Teatro: ensaios e movimentos formativos. Currículo sem Fronteiras, v. 18, n. 2, p. 600-613, maio/ago. 2018.

ALBUQUERQUE JUNIOR, Durval Muniz de. Raros e Rotos, Restos, Rastros e Rostos: os arquivos e documentos como possibilidade do discurso historiográfico. ArtCultura, Uberlândia, v. 15, n. 26, p. 7-28, jan./jun. 2013.

ALCÂNTARA, Celina Nunes de; ICLE, Gilberto. Escrever, Incorporar, Inscreverse: práticas de criação de si na formação teatral. Educação, Porto Alegre, v. 37, n. 3, p. 463-470, set./dez. 2014.

ALMEIDA JUNIOR, José Simões de. Reflexões Acerca do Estágio Curricular na Formação do Professor Licenciado em Teatro. Educação em Revista, Belo Horizonte, v. 29, n. 02, p. 43-64, jun. 2013.

ALMEIDA, Fabrício Moraes de; GALAS, Magna Coeli de Sousa e Silva. Contribuição da Prática da Tecnologia Educacional do Teatro Pedagógico na Formação Docente. Revista Educação e Cultura Contemporânea, v. 11, n. 25, p. 6-59, 2014.

ALVES, Jefferson Fernandes; NASCIMENTO, Anna Karolina Alves do. A Audiodescrição e a Mediação Teatral: a palavra e o jogo dialogando com a cena. Revista FAEEBA, Salvador, v. 27, n. 51, p. 213-231, jan./abr. 2018.

ANDRÉ, Carminda Mendes. O Que Pode a Performance na Escola? Caderno CEDES, Campinas, v. 37, n. 101, p. 83-106, jan./abr. 2017.

AQUINO, Júlio Groppa; VAL, Gisela Maria do. Uma Ideia de Arquivo: contributos para a pesquisa educacional. Pedagogía y Saberes, Bogotá, n. 49, p. 41-53, jul./ dez. 2018.

ARAKAWA-BELAUNDE, Aline Megume; PADILHA, Fernanda Yasmin Odila; RODRIGUES, Anna; SILVEIRA, Isabela Costa. Revista Ibero-Americana de Estudos em Educação, Araraquara, v. 14, n. 2, p. 499-507, abr./jun. 2019.

ATAÍDE, Ana Raquel Pereira de; FREIRE, Morgana Lígia de Farias; SILVEIRA, Alessandro Frederico da. Atividades Lúdicas no Ensino de Ciências: uma adaptação metodológica através do teatro para comunicar a ciência a todos. Educar, Curitiba, n. 34, p. 251-262, 2009.

BAREICHA, Paulo. Psicodrama, Teatro Educação: em busca de conexões. Linhas Críticas, v. 4, p. 121-136, jul./98 a jun./99.

BARROS, Marta Silene Ferreira; BARROS, Priscila Cordeiro Soares; FERREIRA, Ana Letícia; PASCHOAL, Jaqueline Delgado. Arte e Educação: o teatro como recurso metodológico no trabalho pedagógico na alfabetização. Revista IberoAmericana de Estudos em Educação, Araraquara, v. 14, n. 3, p. 1205-1216, jul./ set. 2019

BITAR, Marisa; FERREIRA JR., Amarílio. Pluralidade Linguística, Escola de BêÁ-Bá e Teatro Jesuítico no Brasil do Século XVI. Educação e Sociedade, Campinas, v. 25, n. 86, p. 171-195, abr. 2004. 
BONATTO, Mônica Torres; ICLE, Gilberto. Por uma Pedagogia Performativa: a escola como entrelugar para professores-performers e estudantes-performers. Caderno CEDES, Campinas, v. 37, n. 101, p. 7-28, jan./abr. 2017.

BRITO, Jocilene Oliveira Santos; CRUSOÉ, Nilma Margarida de C. Paulo Freire e o Teatro do Oprimido: experiências formativas de jovens do interior da Bahia. Revista E-Curriculum, São Paulo, v. 16, n. 3, p. 1252-1267, out./dez. 2018.

CABRAL, Beatriz Ângela. Drama como Método de Ensino. São Paulo: Hucitec, 2006.

CABRAL, Beatriz Ângela. Ação Cultural e Teatro como Pedagogia. Sala Preta, São Paulo, v. 12, n. 1, p. 4-17, 2012.

CAETANO, Flávio Henrique; RIBEIRO, Maria Augusta Hermengarda Wurthmann. O Roubo das Conchinhas: da oralidade do Aedo à Oralidade da Cena. Educação: teoria e prática, Rio Claro, v. 02, n. 03, p. 01-05, dez. 1994.

CAON, Paulina Maria. Jogos, Performances e Performatividades na Escola: das experiências corporais à problematização de discursos. Caderno CEDES, Campinas, v. 37, n. 101, p. 107-130, jan./abr. 2017.

CASTRO, Cláudia Maria. O Teatro Como Recurso Pedagógico e Terapêutico no Desenvolvimento Psicossocial do Portador de Deficiência Mental. Revista de Educação Públicas, v. 4, n. 6, jun./dez. 1995.

CEBULSKI, Márcia Cristina; LOOS-SANT'ANA, Helga; SANT’ANA-LOOS, René Simonato. A Arte, a Afetividade e o Sistema Educacional: o desenvolvimento humano em questão. Cadernos de Pesquisa: pensamento educacional, Curitiba, v. 8, n. 20, p. 55-72, set./dez. 2013.

CHACRA, Sandra. Natureza e Sentido da Improvisação Teatral. São Paulo: Perspectiva, 2010.

CINTRA, Rosana; OLIVEIRA, Allyne Nunes de; VEIGA, Elaine. As Contribuições do Lúdico no Processo de Desenvolvimento das Crianças com Síndrome de Down na Educação Infantil. Horizontes, v. 33, n. 2, p. 159-166, jul./dez. 2015. CONTE, Elaine; HABOWSKI, Adilson Cristiano; SILVA, Raquel Silva da. O Teatro na Educação: avaliações e debates em voga. Revista Cocar, Belém, n. 5, p. 163184, jan./abr. 2019.

COSTA, Cristiano da; MUNHOZ, Angélica; SCHNEIDER, Cristiane. Do Jogo Teatral ao Teatro como Criação. Imagens da Educação, v. 6, n. 2, p. 67-74, 2016.

COUTINHO, Andréa Senra; OLIVEIRA, Bruna Tontes de. Direito à Arte É Direito de Conhecer Arte, Produzindo Arte. Educação em Foco, Juiz de Fora, Edição Especial, p. 133-149, fev. 2015.

COUTINHO, Karyne Dias. Por uma Didática da Improvisação. Em Aberto, Brasília, v. 31, n. 101, p. 121-132, jan./abr. 2018.

DAL-FARRA, Rossano André; GONÇALVES, Fernanda Carneiro. A Educação Libertadora de Paulo Freire e o Teatro na Educação em Saúde: experiências em uma escola pública no Brasil. Pro-Posições, Campinas, v. 29, n. 3, p. 401-422, set./dez. 2018.

DANTAS, Osmarina Maria dos Santos; NAKAYAMA, Luiza; SANTANA, André Ribeiro de. Teatro de Fantoches na Formação Continuada Docente em Educação Ambiental. Educação e Pesquisa, São Paulo, v. 38, n. 03, p. 711-726, jul./set. 2012.

DIDI-HUBERMAN, Georges. Quando as Imagens Tocam o Real. Pós, v. 2, n. 4, p. 204-219, nov. 2012.

Educação \& Realidade, Porto Alegre, v. 46, n. 3, e104309, 2021. 
Um Arquivo sobre Teatro e Educação

FARGE, Arlete. O Sabor de Arquivo. São Paulo: Edusp, 2009.

FARIA, Alessandra Ancona de. Paredes de Vidro: reflexões sobre a falta de diálogo docente. EccoS - Revista Científica, São Paulo, n. 35, p. 67-82, set./dez. 2014. FOUCAULT, Michel. Tecnologias de si. Verve, São Paulo, n. 6, p. 321-60, 2004.

FOUCAULT, Michel. Michel Foucault explica seu último livro. In: FOUCAULT, Michel. Ditos e Escritos II. Rio de Janeiro: Forense Universitária, 2008a. P. 145146.

FOUCAULT, Michel. Nascimento da Biopolítica. Curso no Collége de France (1978-1979). São Paulo: Martins Fontes, 2008b.

FOUCAULT, Michel. Sobre as maneiras de escrever a história. In: FOUCAULT, Michel. Ditos e Escritos II. Rio de Janeiro: Forense Universitária, 2008c. P. 72.

FOUCAULT, Michel. O uso dos prazeres e as técnicas de si. In.: FOUCAULT, Michel. Ditos e Escritos V. p. Rio de Janeiro: Forense Universitária, 2010. P. 192-217. FOUCAULT, Michel. O nascimento de um mundo. In: FOUCAULT, Michel. Ditos e Escritos X. Rio de Janeiro: Forense Universitária, 2014. P. 52.

FRAGA, Laura Pippi; HUNDERTMARCK, Jucilene; POZEBON, Simone; SILVA, Daiane Susara Garcez da; LOPES, Anemari Roesler Luersen Vieira; PEREIRA, Patrícia Sandalo. Situações de Aprendizagem Compartilhadas: o caso da contagem por agrupamento. Revista Eletrônica de Educação, São Carlos, v. 6, n. 1, p. 129-147, maio 2012.

FREITAS, Nívia Magalhães da Silva; GONÇALVES, Terezinha Valim Oliver. Práticas Teatrais e o Ensino de Ciências: o teatro jornal na abordagem da temática do lixo. Educar em Revista, Curitiba, Brasil, v. 34, n. 68, p. 199-216, mar./abr. 2018.

GOHN, Maria da Glória; HANSTED, Talitha Cardoso. Teatro e Educação: uma relação historicamente construída. EccoS - Revista Científica, São Paulo, n. 30, p. 199-220, jan./abr. 2013.

GRAZIOLI, Fabiano Tadeu. Os Princípios Gerais do Teatro na Escola e o Afastamento da Atividade Teatral Significativa da Escola Brasileira. Roteiro, Joaçaba, v. 33, n. 1, p. 7-24, jan./jun. 2008.

HARTMANN, Luciana. 'Eles Brincam de Guerra Mundial': protagonismo infantil em narrativas de crianças imigrantes. Educação em Foco, Juiz de Fora, v. 23, n. 3, p. 923-942, set./dez. 2018.

ICLE, Gilberto; PEREIRA, Marcelo de Andrade. Pedagogia Performativa e seus Não-Lugares: reverberações da khôra a partir de Platão, Derrida e Agamben. Educar em Revista, Curitiba, v. 34, n. 67, p. 121-137, jan./fev. 2018.

ICLE, Gilberto; PEREIRA, Marcelo de Andrade; SCHECHNER, Richard. O Que Pode a Performance na Educação? Educação \& Realidade, Porto Alegre, v. 35, n. 02, p. 23-36, maio/ago. 2010.

IPOLITO, Michelle; PERDIGÃO-NASS, Daniel. Artes Cênicas na Discussão do Tema Privacidade. Revista de Educação, Ciência e Cultura, v. 21, n. 2, p. 227-245, jul./dez. 2016.

JAPIASSU, Ricardo Ottoni. Ensino do Teatro e Políticas Educacionais. Revista da FAEEBA, Salvador, n. 10, p. 181-210, jul./dez. 1998.

JAPIASSU, Ricardo Ottoni. O Ensino do Teatro nas Séries Iniciais da Educação Básica: a formação de conceitos sociais no jogo teatral. 1999. Dissertação (Mestrado em Artes Cênicas) - Escola de Comunicação e Artes (ECA), Universidade de São Paulo, São Paulo, 1999. 
JAPIASSU, Ricardo Ottoni. Par ou Ímpar? jogos teatrais e conceitos matemáticos. Cadernos de Educação, Pelotas, n. 14, p. 123-140, jul./dez. 2000.

JAPIASSU, Ricardo Ottoni. A Linguagem Teatral na Escola: pesquisa, docência e prática pedagógica. Campinas: Papirus, 2007.

JAPIASSU, Ricardo Ottoni. Metodologia do Ensino de Teatro. Campinas: Papirus, 2009.

KOUDELA, Ingrid Dormien. Jogos Teatrais. São Paulo: Perspectiva, 1992.

KOUDELA, Ingrid Dormien. Texto e Jogo. São Paulo: Perspectiva, 1999.

KRUPPA, Sonia. Portalla; VOLTAS, Fernanda Quatorze. O Teatro na Formação dos Educandos: as percepções dos educadores de um centro educacional unificado (CEU) da cidade de São Paulo. Revista e-Curriculum, São Paulo, v. 14, n. 01, p. 307-331 jan./mar. 2016.

MACHADO, Marina Marcondes. A Criança é performer. Educação \& Realidade, Porto Alegre, v. 35, n. 02, p. 115-138, maio/ago. 2010.

MACHADO, Marina Marcondes. Fazer Surgir Antiestruturas: abordagem em espiral para pensar currículo em arte. Revista E-Curriculum, São Paulo, v. 8, n. 1, p. 1-21, abr. 2012.

MACHADO, Roberto. Impressões de Michel Foucault. São Paulo: N-1 Edições, 2017. MEDINA, Alice Maria Corrêa. A Ressignificação de Objetos Realizada por Crianças no Contexto Hospitalar. Revista Educação em Questão, Natal, v. 56, n. 50, p. 219-268, out./dez. 2018.

OLIVEIRA, Maria Eunice de; STOLTZ, Tania. Teatro na Escola: considerações a partir de Vygotsky. Educar, Curitiba, n. 36, p. 77-93, 2010.

OLIVEIRA, Thiago Ranniery; PARAÍSO, Marlucy. Currículo, Cultura e Crueldade: para compor uma ética com Antonin Artaud e o teatro. Perspectiva, Florianópolis, v. 31, n. 2, 615-644, maio/ago. 2013.

OLIVEIRA, Thiago Ranniery Moreira de; PARAÍSO, Marlucy Alves. Theatrum Curriculum: sobre o duplo ver e pintar em currículo com Antonin Artaud e o teatro. Revista e-Curriculum, São Paulo, v. 12, n. 01, p. 948-968, jan./abr. 2014.

PEREIRA, Marcelo de Andrade. Pedagogia da Performance: do uso poético da palavra na prática educativa. Educação \& Realidade, Porto Alegre, v. 35, n. 2, p. 139-158, maio/ago. 2010.

PEREIRA, Marcelo de Andrade. Performance e Educação: relações, significados e contextos de investigação. Educação em Revista, Belo Horizonte, v. 28, n. 01, p. 289-312, mar. 2012.

PEREIRA, Marcelo de Andrade. Performance e Educação: configurações parateatrais da docência. Educação, Santa Maria, v. 39, n. 3, p. 505-514, set./dez. 2014.

PERIC, Thereza. No Exercício da Arte: o professor criador. Diálogo entre o fazer artístico e a prática pedagógica. Pro-Posições, Campinas, v. 24, n. 2, p. 195-220, maio/ago. 2013.

PIERI, Helena; ROSA, Cleci. Teatro Como Recurso Didático Para Contextualizar a Física: análise de uma atividade com estudantes do ensino médio. Imagens da Educação, v. 7, n. 2, p. 38-44, 2017.

PUPO, Maria Lúcia de Souza Barros. No Reino da Desigualdade. São Paulo: Perspectiva, 1991.

PUPO, Maria Lúcia de Souza Barros. Palavras em Jogo: textos literários e teatroeducação. 1997. Tese (Livre Docência) - Escola de Comunicação e Artes (ECA), Universidade de São Paulo, São Paulo, 1997.

Educação \& Realidade, Porto Alegre, v. 46, n. 3, e104309, 2021. 
Um Arquivo sobre Teatro e Educação

PUPO, Maria Lúcia de Souza Barros. Para Desembaraçar os Fios. Educação \& Realidade, Porto Alegre, v. 30, n. 2, p. 217-228, jul./dez. 2005.

RABELLO, Roberto Sanches. O Teatro na Educação do Deficiente Visual e a Teoria da Peça Didática de Brecht. Revista da FAEEBA, Salvador, v. 16, n. 27, p. 159-168, jan./jun., 2007.

REVERBEL, Olga. Jogos Teatrais na Escola. São Paulo: Scipione, 1989.

REVERBEL, Olga. Um Caminho do Teatro na Escola. São Paulo: Scipione, 1997.

RYNGAERT, Jean-Pierre. Jogar, Representar: práticas dramáticas e formação. São Paulo: Cosac Naify, 2009.

SANTOS, Vera Lúcia Bertoni dos. Experiência Urbana e Conhecimento Teatral: romper limites e ampliar espaços. Educação \& Realidade, Porto Alegre, v. 30, n. 2, p. 230-242, jul./dez. 2005

SERRANO JUNIOR, Jehu Viera. Deixando de Carregar Água em Peneiras: as contribuições do teatro do oprimido em Mato Grosso do Sul. QUAESTIO, Sorocaba, v. 10, n. 1/2, p. 281-297, maio/nov. 2008.

SPOLIN, Viola. Improvisação para o Teatro. São Paulo: Perspectiva, 2015.

THOMAZ, Sueli Barbosa. O Jogo Dramático e o Imaginário de Alunos nas Aulas de Teatro. Práxis Educativa, Ponta Grossa, v. 2, n. 1, p. 43-50, jan./jun. 2007.

TROJA, Rose Meri. A Arte e a Humanização do Humano: afinal de contas, para que serve a arte? Educar, Curitiba, n. 12, p. 87-96, jan./dez. 1996.

VEYNE, Paul. Foucault, o Pensamento, a Pessoa. Lisboa: Edições Texto e Grafia, 2009.

VIANNA, Tiche; STRAZZACAPPA, Márcia. Teatro na Educação: reinventando mundos. In: FERREIRA, Sueli (Org.). O Ensino das Artes: construindo caminhos. Campinas: Papirus, 2001. P. 115-138.

VIEIRA, Marcílio de Souza. Foucault e a pesquisa educacional em arte. Revista Educação em Questão, Natal, v. 33, n. 19, p. 150-166, set./dez. 2008.

ZILIANI, Rosemeire de Lourdes Monteiro. Invenção da identidade Sul-MatoGrossense no teatro de uma escola técnica. Acta Scientiarum Education, Maringá, v. 35, n. 2, p. 255-262, jan./jun. 2013.

ZILIANI, Rosemeire de Lourdes. Escritos e Invenções da Experiência do Grupo Teatral Cera: outros ditos, outros espaços-tempos. Perspectiva, Florianópolis, v. 34, n. 2, p. 717-737, maio/ago. 2016.

Sidmar Silveira Gomes é Professor Adjunto do Departamento de Música e Artes Cênicas da Universidade Estadual de Maringá, atuando no curso de Artes Cênicas - Licenciatura em Teatro.

ORCID: http://orcid.org/0000-0003-4177-2464

E-mail: sidmar.gomes@uol.com.br

Editora-Responsável: Fabiana de Amorim Marcello

Este é um artigo de acesso aberto distribuído sob os termos de uma Licença Creative Commons Atribuição 4.0 Internacional. Disponível em: <http:// creativecommons.org/licenses/by/4.0>. 